\title{
A Study of an Air Scouring Integral Immersed Hollow Fiber Membrane Module for Energy Saving and Membrane Fouling Control
}

\author{
Hyun-Hoon Jung ${ }^{1,2} \cdot$ Ji-Yun Seon ${ }^{1 \odot} \cdot$ Tea-Hyoung Lim ${ }^{1 \odot} \cdot$ Seung-Mok Lee ${ }^{2,+\odot} \cdot$ \\ Seung-Kyun Park ${ }^{1,++}$ \\ 'Seojin Energy Co., Ltd. \\ ${ }^{2}$ Department of Environmental Engineering, Catholic Kwandong University
}

(Received May 28, 2021; Revised July 5, 2021; Accepted July 14, 2021)

Objectives: MBR (Membrane BioReactor) is well established wastewater treatment that combines biological and physical method with high quality effluent. The purpose of this study is to utilize an air scouring integral immersed hollow fiber membrane module through efficient structural improvement developed to reduce membrane fouling. In addition, the scouring aeration was optimized to determine the energy savings.

Methods: In this study, membrane fouling test was evaluated in various of scouring aeration flow with range of 40 to $140 \mathrm{~m}^{3}$ air $/ \mathrm{m}^{2}$ projected area $\cdot \mathrm{hr}$ and influent and effluent was analyzed by water quality standard.

Results and Discussion: In scouring aeration test, effective membrane contamination control was possible with supplying $80 \mathrm{~m}^{3}$ air $/ \mathrm{m}^{2}$ projected area $\cdot \mathrm{hr}$, scouring aeration rate gradually increased the differential pressure from below $60 \mathrm{~m}^{3}$ air $/ \mathrm{m}^{2}$ projected area $\cdot \mathrm{hr}$, which accelerates the membrane contamination phenomenon. By reducing more than $20 \%$ of the existing general scouring aeration rate of $100 \sim 140 \mathrm{~m}^{3}$ air $/ \mathrm{m}^{2}$ projected area $\cdot \mathrm{hr}$, electricity and maintenance costs can be reduced due to aeration control, and at the same time, it is confirmed that the technology has the same performance. The pilot test results of SJMBR with the developed module showed that the effluent was BOD of $1.4 \mathrm{mg} / \mathrm{L}$, COD of $4.2 \mathrm{mg} / \mathrm{L}$, SS of $0.7 \mathrm{mg} / \mathrm{L}$, T-N of $5.56 \mathrm{mg} / \mathrm{L}$, T-P of $0.56 \mathrm{mg} / \mathrm{L}$, total coliform group of $0 \mathrm{ea} / \mathrm{mL}$, and ecotoxicity of $0 \mathrm{TU}$, respectively.

Conclusions: These results are combined, when using an air scouring integral immersed hollow fiber membrane module, it is expected to reduce the amount of scouring air by more than $20 \%$ by optimizing the supply of scouring air. In addition, it can also be determined by technology that satisfy the same permeability and treated water quality as existing technologies.

Keywords: Membrane, Integral Module, Membrane Fouling, Air Scouring, Energy Saving

\author{
Corresponding author \\ E-mail: leesm@cku.ac.kr \\ Tel: 033-469-7535 \\ ${ }^{\dagger \dagger}$ Corresponding author \\ E-mail: skpark@seojinl.com \\ Tel: 02-2601-5310 Fax: 02-2601-5312 \\ (C) 2021, Korean Society of Environmental Engineers
}

(c) This is an Open Access article distributed under the terms of
the Creative Commons Attribution Non-Commercial License
(http://creativecommons.org/licenses/by-nc/4.0/) which permits provided the original work is properly cited. 


\title{
연구논문
}

\section{에너지 저감 및 막 오염 제어를 위한 공기세정 일체형 중공사막 모듈 연구}

\author{
정현훈 $^{1,2 \odot ~} \cdot$ 선지윤 $^{1 \odot} \cdot$ 임태형 $^{1 \odot ~} \cdot$ 이승목 $^{2,+\odot ~} \cdot$ 박성균 $^{1,++}$ \\ ${ }^{1}$ (주)서진에너지 \\ 2가톨릭관동대학교 환경공학과
}

목적 : MBR (Membrane BioRactor)은 생물반응조와 분리막을 결합하여 하·폐수를 처리하는 기술로, 고품질 처리수 생산이 가능하여 각광 받는 기술이다. 본 연구 목적은 막 오염을 제어를 위해 효율적인 구조로 개선된 모듈을 개발 하고, 개발된 세정공기 일체형 침지식 중공사막 모듈을 활용하는 것이다. 또한, 에너지 저감을 위한 세정공기 공급 량의 최적화 방안에 대해 연구하였다.

방법 : 본 연구에서는 세정공기 일체형 침지식 중공사막 모듈을 이용하여 $40.0 ~ 140.0 \mathrm{~m}^{3} \mathrm{air} / \mathrm{m}^{2}$ projected area·hr까 지 세정공기의 단계별 공급에 따른 막 오염 현상을 실험하고, 추가로 처리수의 수질분석을 실시하였다.

결과 및 토의 : 세정공기 공급량을 단계적으로 조절하여 실험한 결과, $80 \mathrm{~m}^{3} \mathrm{air} / \mathrm{m}^{2}$ projected area $\cdot \mathrm{hr}$ 까지의 공급량 으로 효율적인 막 오염 제어가 가능하였으며, $60 \mathrm{~m}^{3} \mathrm{air} / \mathrm{m}^{2} \mathrm{projected} \mathrm{area} \cdot \mathrm{hr}$ 이하부터 투과압력이 점진적으로 증가 하여 막 오염 현상이 가속화되었다. 기존 $100 \sim 140 \mathrm{~m}^{3} \mathrm{air} / \mathrm{m}^{2} \mathrm{projected} \mathrm{area} \cdot \mathrm{hr}$ 의 일반적인 세정공기 공급량과 비교 시 $20 \%$ 이상의 공급량을 저감함으로써 송풍기 조절에 따른 전기·유지비 저감이 가능하였다. 이와 동시에 투과성 능 또한 기존과 동등한 것으로 확인됐다. 개발된 모듈을 적용한 SJMBR의 pilot test 실험결과, 처리수질은 $\mathrm{BOD}$ $1.4 \mathrm{mg} / \mathrm{L}, \mathrm{COD} 4.2 \mathrm{mg} / \mathrm{L}, \mathrm{SS} 0.7 \mathrm{mg} / \mathrm{L}, \mathrm{T}-\mathrm{N} 5.56 \mathrm{mg} / \mathrm{L}, \mathrm{T}-\mathrm{P} 0.56 \mathrm{mg} / \mathrm{L}$, 총대장균군 $0 \mathrm{ea} / \mathrm{mL}$, 생태독성 $0 \mathrm{TU}$ 등이 었다.

결론: 결과들을 종합하면 공기세정 일체형 중공사막 모듈 이용할 시, 세정공기 공급량을 최적화하여 기존 대비 $20 \%$ 이상 세정 공기량을 저감 효과를 기대할 수 있으며, 기존과 동등한 투과성능 및 처리수질 만족에 부합하는 기술로 판단할 수 있다.

주제어: 분리막, 일체형 모듈, 막 오염, 세정공기, 에너지 저감

\section{1. 서 론}

급격한 도시화 및 산업화, 폭발적인 인구증가는 심각한 수 질오염과 수자원의 고갈이 가속화됨에 따라 수자원과 물 재이 용에 대한 수요가 지속적으로 증가하고 있는 추세이다. ${ }^{1,2)}$ 이 러한 상황 속에서 산업은 빠른 속도로 고도화되고 있으며, 이 에 따라 유입되는 오염물질의 양 또한 증가 되고 있다. 이와 더불어 법적 기준은 지속적으로 강화되고 있어, 기존 처리 방 식으로는 요구하는 만큼까지 만족하지 못하는 한계에 도달한 실정이다.

현재 기존 처리 방식을 대체하거나 개선할 수 있는 처리 기술에 대한 연구가 활발히 진행되고 있으며, 그 중 MBR (membrane bioReactor) 기술은 기존 처리기술을 대체하거나 개선하기에 용이한 장점과 함께, 강화되고 있는 처리기준에
만족할 수 있는 최적의 기술로 각광 받고 있다.-6) 또한, $\mathrm{MBR}$ 기술은 기존 활성슬러지 공정의 1 차 침전조, 생물반응조, 2 차 침전조, 여과, 소독조 등의 복잡한 공정을 단순화 할 수 있는 장점이 있으며 ${ }^{7,8)}$, 오염물질을 분해하면서 전기를 생산하고, 동시에 에너지를 저감할 수 있는 전기화학적 반응과 연계한 분리막 기반의 기술도 해수 및 폐수 처리분야의 미래기술로 주목받고 있다. ${ }^{9)}$

그러나 분리막 기술에는 막 오염(membrane fouling)이라는 큰 단점을 내포하고 있는 기술로 막 오염은 미생물 및 콜로이 드 입자층의 막 표면 퇴적, 흡착성 물질에 의한 흡착 등 여러 가지 요인에 기인하여 막 표면에 오염물질이 축적되고 ${ }^{8,10)}$, 막 공극의 유효면적을 감소시켜 투과성능을 저하시킴과 동시에 막 수명이 단축시키게 된다. ${ }^{7,8}$

이러한 막 오염을 억제하기 위한 방법으로 세정공기(air 

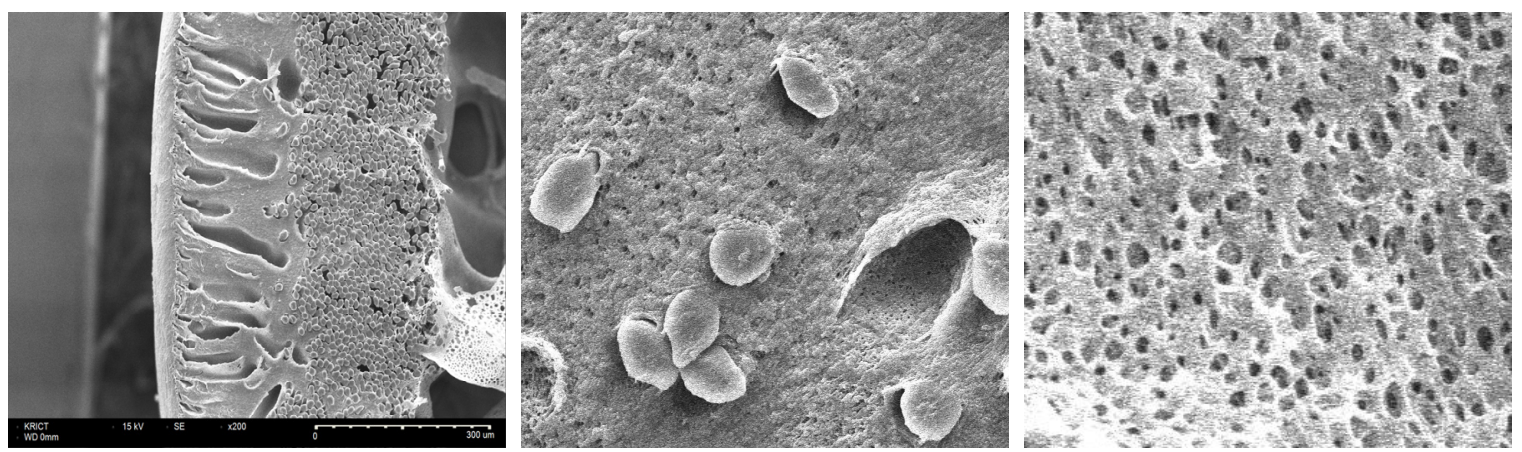

Fig. 1. The SEM image of SJMBR hollow fiber membrane.

scouring)를 막 표면에 공급하여 제어할 수 있다. ${ }^{10-12)}$ 기존에 는 $3 \mathrm{~mm}$ 미만의 미세 기포를 공급하는 반면에 최근에는 세정 공기 기포의 크기가 $6 \sim 8 \mathrm{~mm}$ 인 조대기포를 이용하는 것이 세정효과가 높게 나타나고 있다. 현재까지 막 오염과 기포 크 기와 관련된 역학적 관계에 대한 복합적인 상호작용은 정확하 게 규명되지는 않았지만, 기포의 크기가 커질수록 세정효과가 높아지는 것으로 알려져 있다. ${ }^{13)}$

그러나 하수처리시설의 연간 에너지 소비량 중 전체 소비량 의 $98.6 \%$ 가 전력사용량에 해당되는 것으로 알려져 있으며, 이 중 송풍기의 전략사용량은 $40.1 \%$ 로 가장 높은 비중을 차지 하고 있어 막 오염을 제어하기 위해 공급하는 세정공기의 과 도한 공급은 오히려 유지비용 증가를 초래하고 있는 실정이 다. ${ }^{14)}$ 또한, 기존 연구결과에 따르면 막 오염 저감을 위해 공급 하는 세정공기를 필요 이상으로 공급하더라고 효과가 증가하 지 않은 것으로 밝혀져, 과도하게 공급되는 세정공기량을 최 적화할 수 있는 것으로 알려져 있다. ${ }^{15)}$

이에 에너지 저감을 위해 분리막에 공급하는 세정공기량의 최적화가 필요하며, 이러한 기술에 대한 연구가 중점적으로 진 행되어야 한다. ${ }^{16)}$ 그러나, 현재까지 MBR 시스템적 측면의 에 너지 저감 연구에 관한 몇 차례 연구사례가 있을 뿐 ${ }^{15}$, 에너지 저감을 위한 모듈의 연구가 거의 진행되지 않은 실정이다. ${ }^{17}$ 또한, 모듈과 산기관의 효율적 일체형 구조에 대한 연구 사례는 전무한 상황으로 ${ }^{16)}$, 산기관이 일체화된 공기세정 일체형 모듈 개발을 통해 효율적인 세정공기 공급이 필요하다고 판단된다.

이에 본 연구에서는 세정공기량 공급 저감이 가능하도록 개 발한 SJMBR (SEOJIN Membrane BioReactor) 공기세정 일체 형 침지식 중공사막 모듈 제작을 통하여 분리막 모듈의 특성 을 파악하고, 공급되는 세정공기량의 최적화를 위한 pilot test 를 통해 에너지 저감 효과를 평가하고자 한다.

\section{2. 재료 및 방법}

\section{1. 재료 및 방법의 특성}

\subsubsection{PVDF 재질의 특성}

PVDF (polyvinylidene fluoride)는 현재 전세계 분리막 분야
에서 가장 널리 사용되는 분리막 소재로, 제막 시 다른 소재들 에 비해 매우 좁은 범위의 기공분포로 안정되게 구현할 수 있는 장점이 있으며 대부분 0.04 부터 $0.4 \mu \mathrm{m}$ 범위 내로 제조 할 수 있다. ${ }^{17)} \mathrm{PVDF}$ 는 상용화된 분리막 소재 중 가장 우수한 화학적 내구성을 지니고 있으며, 오염 시 강한 조건의 산, 염 기, 염소 세정을 통해 보다 완벽하게 여과성능을 회복시킬 수 있는 장점이 있다. ${ }^{16)}$ 단, $\mathrm{pH} 10$ 이상에서는 PVDF 사슬 내 불소가 일부 떨어져 나오면서 탄소 간 이중결합을 부분적으로 형성하면서 노란색에서 심하게는 갈색, 검은색으로까지 변색 되는 경우가 있는 것으로 알려져 있으나, 물성에 큰 변화는 없는 것으로 알려져 있다. ${ }^{18)}$ 본 연구에서는 비용매 유도 상분 리법(non-solvent induced phase separation, NIPS)으로 제작한 $\mathrm{PVDF}$ 중공사막을 사용하였다.

\subsection{2. 중공사막의 특성}

본 연구에 사용한 SJMBR 중공사막(hollow fiber membrane) 은 3중 구조의 친수코팅된 침투융합형 PVDF 중공사막으로, SEM image는 Fig.1과 같고, 중공사막의 특성에 대한 분석결 과는 Table 1과 같다. 중공사막은 평막(flat sheet membrane) 에 비해 집적도가 높고, 내부 지지체로 인해 인장강도가 높으 며, 내화학성이 우수하다는 장점이 있다. ${ }^{18)}$

\subsection{3. 공기세정 일체형 중공사막 모듈의 특징}

일반적으로 분리막 분야에서 사용하는 모듈이라 함은 일정 한 개수의 분리막을 균일한 형태의 용기 안에 설치하여 일체 화하거나 묶음 형태로 하여 여과 기능이 가능하도록 제작한 것을 말한다. ${ }^{8)}$

Table 1. Specification of membrane module use in this study.

\begin{tabular}{cc} 
Item & Value \\
Pore size & $0.0278 \mu \mathrm{m}$ (mean) \\
\hline Contact angle & $76.48^{\circ}$ \\
\hline Tensile strength & $182.0 \mathrm{~N} /$ filament \\
\hline Outer/inner diameter & $2.0 \mathrm{~mm} / 1.2 \mathrm{~mm}$ \\
\hline Structure & Three layer structure \\
\hline
\end{tabular}




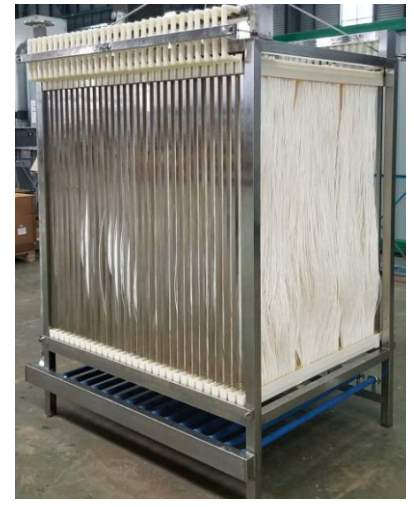

(a)

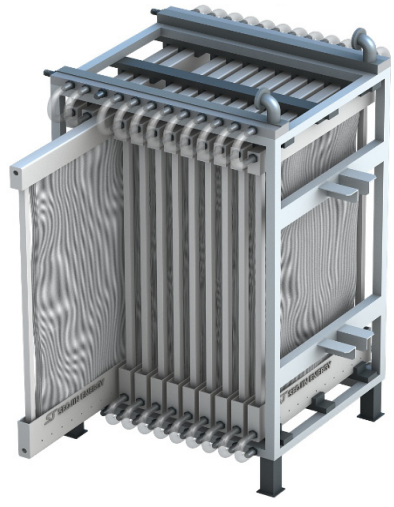

(b)
Fig. 2. The photograph of (a) general frame type and (b) SJMBR frame type with integral air scouring system.

분리막의 모듈화는 집적도를 높여 소요부지를 축소하는 측 면에서 운영관리에 유리하기 때문에 모든 분리막은 모듈화하 여 제작되며, 모듈은 처리용량 및 현장여건에 따라 필요한 부 속품 또는 장치를 포함한 상자형의 프레임(frame)을 제작하게 된다.

또한, 일반적인 침지식 분리막의 경우, 프레임 하부에 별도 의 산기관을 갖춘 형태로, 별도의 산기관을 통해 세정공기를 공급하게 된다.

일반적인 분리막 모듈과 결합된 프레임 형태는 Fig. 2(a)와 같다. 이러한 일반적인 프레임의 경우, 공급되는 일부의 공기 가 프레임 외부로 빠져나갈 여지가 있어 분리막 표면에 직접 적인 공급에 불리한 단점이 있다.

이러한 단점을 해결하기 위해 공급되는 일부의 공기가 프레 임 외부로 빠져나가지 않도록 효율적인 구조로 개선할 필요가 있다. 이러한 단점을 개선하기 위해 고안한 본 연구에 사용되 는 공기세정 일체형 중공사막 모듈과 결합된 프레임의 형태는 Fig. 2(b)와 같고, 공기세정 일체형 중공사막 모듈의 구조와
구성은 Fig. 3(a) (d)와 같다.

본 연구에서 사용되는 SJMBR 모듈은 세정공기 공급 산기 관 일체형 구조로 구현되어 분리막 표면으로 공급이 수월하 여, 막 표면으로 보다 직접적인 세정공기 공급이 가능하도록 설계되었다. 또한, 일체화된 산기관은 내부 격벽 구조로 구성 되어 간헐적 공기공급(undefined aeration system)을 통해 공 급량을 최적화하도록 하였으며, 이에 따라 전력량을 감소 통 한 에너지 저감이 가능토록 고안되었다.

\section{2. 실험재료 제조방법}

\subsection{1. 일체형 중공사막 모듈 제작 방법}

일체형 중공사막 모듈은 중공사막 다발을 모듈 potting case 에 가지런히 삽입한 후, 상·하에 에폭시(epoxy)를 potting하고 좌·우 측면에 파이프관을 접속하여 완성하였다. 모듈의 완성 형태는 Fig.4(a)와 같으며, 연구를 위해 제작한 test type 프레 임 형태는 Fig. 4(b)와 같다.

\section{3. 실험 조건 및 방법}

막 오염은 세정공기 공급을 통해 제어할 수 있으며, 제조사 별로 다소 차이가 있지만, 일반적으로 투영면적별 100 140 $\mathrm{m}^{3} / \mathrm{m}^{2}$ frame projected area $\cdot \mathrm{hr}$ 를 공급한다.

본 실험에서는 공기세정 일체형 중공사막 모듈(막 면적 28.0 $\mathrm{m}^{2}$ )을 이용하여 $40 \sim 140 \mathrm{~m}^{3} \mathrm{air} / \mathrm{m}^{2}$ projected area $\mathrm{hr}$ 범위에서 투영면적당 세정공기의 공급량에 따른 막 오염 현상을 실험하 였으며, 처리수에 대한 수질분석을 실시하였다.

SJMBR pilot plant의 평면도는 Fig. 5 와 같고, $12,000 \mathrm{~mm}$ $\times 3,000 \mathrm{~mm}$ 의 $40 \mathrm{ft}$ 특수컨테이너로, 용량은 최대 $15.0 \mathrm{~m}^{3} / \mathrm{d}$ 처리가 가능하도록 제작하였다. SJMBR pilot plant는 유량조 정조-무산소조-호기/분리막조-처리조로 구성하였으며, 실험 공간은 $\mathrm{C}$ 시 하수처리장 내 유입분배조 후단의 제공장소에 설

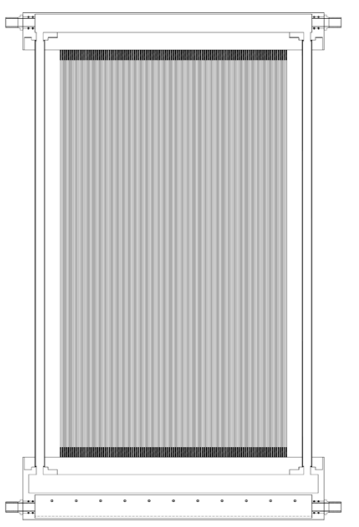

(a)

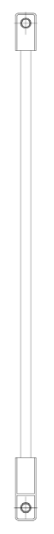

(b)

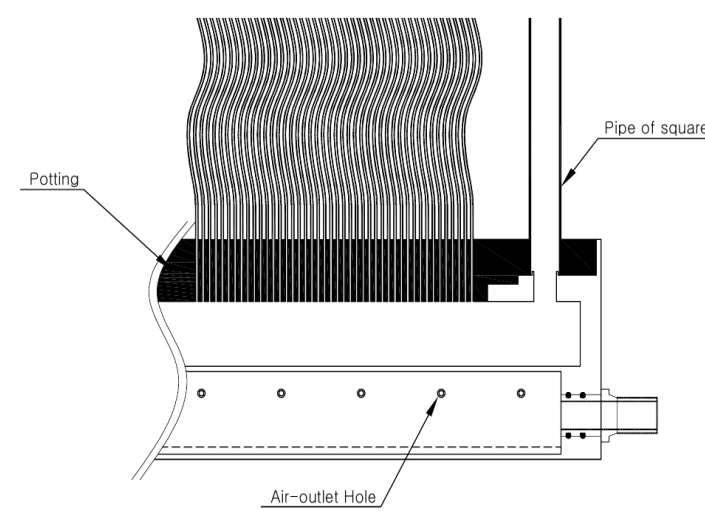

(c)

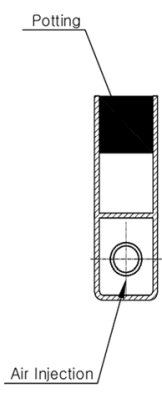

(d)

Fig. 3. The fabrication drawing of an air scouring integral immersed hollow fiber membrane module: (a) front view, (b) side view, (c) detailed front view, (d) detailed side view. 


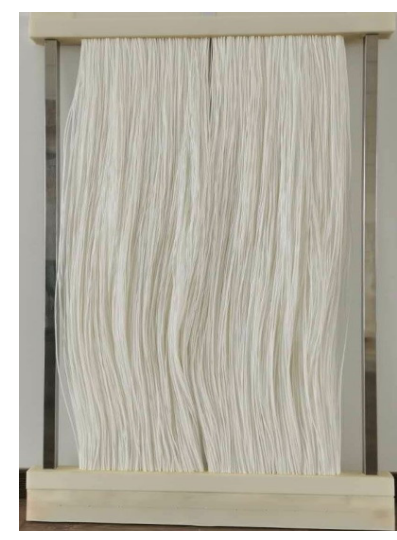

(a)

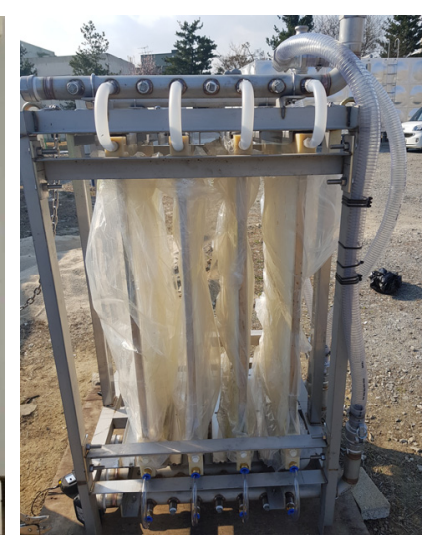

(b)
Fig.4. The completed form of an air scouring integral hollow fiber membrane module (a) and SJMBR frame for pilot test type (b).

치하여 진행하였다(Fig. 6).

유입수는 $\mathrm{C}$ 시 하수처리장 유입분배조를 거쳐 제공되는 원 수를 사용하여 실험을 진행하였으며, 제공되는 유입수 수질분 석 결과는 Table 2와 같다.

실험조건은 호기조의 MLSS 농도를 $8,000 \mathrm{mg} / \mathrm{L}$ 로 실험기
Table 2. Characteristic of influent in this study.

\begin{tabular}{cc} 
Item & Value \\
BOD & $94.1 \mathrm{mg} / \mathrm{L}$ \\
\hline COD & $51.9 \mathrm{mg} / \mathrm{L}$ \\
\hline SS & $82.0 \mathrm{mg} / \mathrm{L}$ \\
\hline T-N & $39.54 \mathrm{mg} / \mathrm{L}$ \\
\hline T-P & $2.68 \mathrm{mg} / \mathrm{L}$ \\
\hline Total coliform group & $470 \mathrm{ea} / \mathrm{mL}$ \\
\hline Ecotoxicity & $0.5 \mathrm{TU}$ \\
\hline
\end{tabular}

간 내 일정하게 유지하면서, 투과플럭스는 $0.5 \mathrm{~m}^{3} / \mathrm{m}^{2} \cdot \mathrm{d}$ 로 유 지하여 진행하였다. 투과플럭스는 $0.5 \mathrm{~m}^{3} / \mathrm{m}^{2} \cdot \mathrm{d}(21.0 \mathrm{LMH})$ 의 정유량 제어방식으로 제어하여 8 분 가동, 2 분 정지로 진행하 였다(Fig.7). 실험기간 동안에는 별도의 분리막 세정을 진행 하지 않았다.

또한, $\mathrm{MBR}$ 공정의 공기세정량의 운영값을 도출하기 위해 막 면적당 공기량인 $\mathrm{SAD}_{m}$ (specific aeration demand per membrane surface area, $\mathrm{Nm}^{3} / \mathrm{m}^{3} \cdot \mathrm{hr}$ )와 투과수와 공기량의 비 인 $\mathrm{SAD}_{p}$ (specific aeration demand per permeate volume, $\mathrm{Nm}^{3} / \mathrm{m}^{2}$ )을 아래 식을 이용하여 산출하였으며, 분리막의 산출

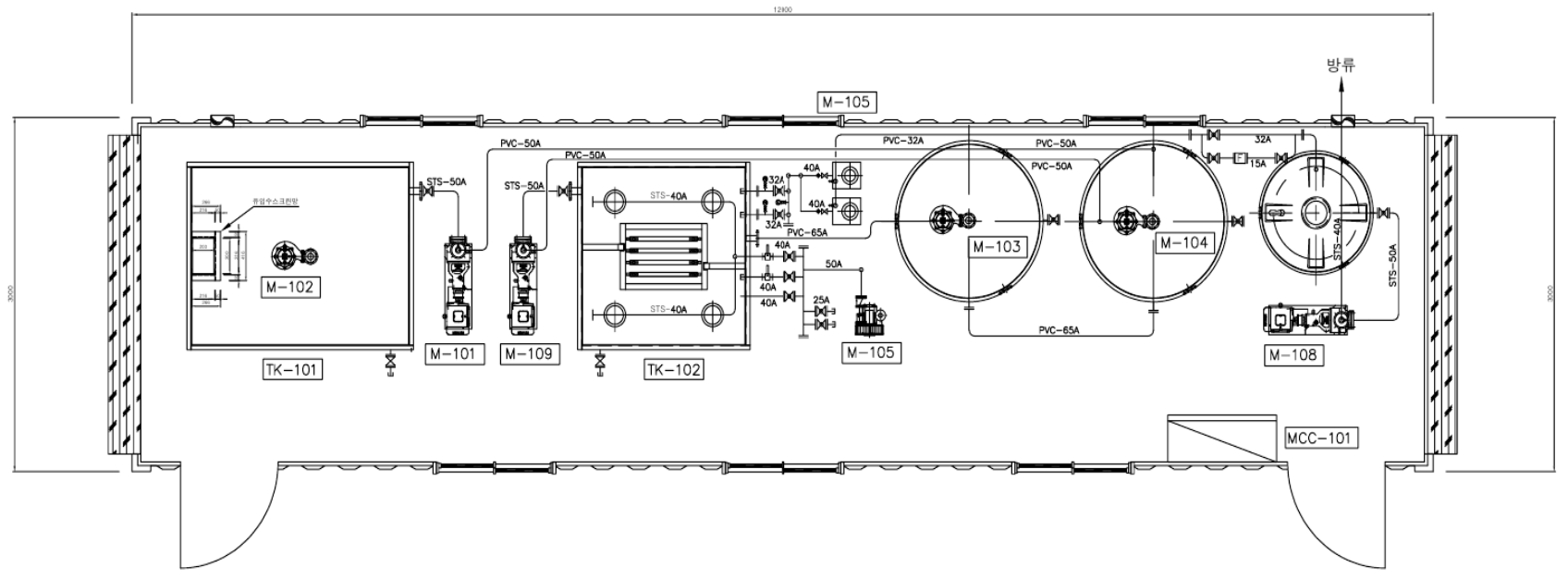

Fig. 5. Section plan of the SJMBR pilot plant.

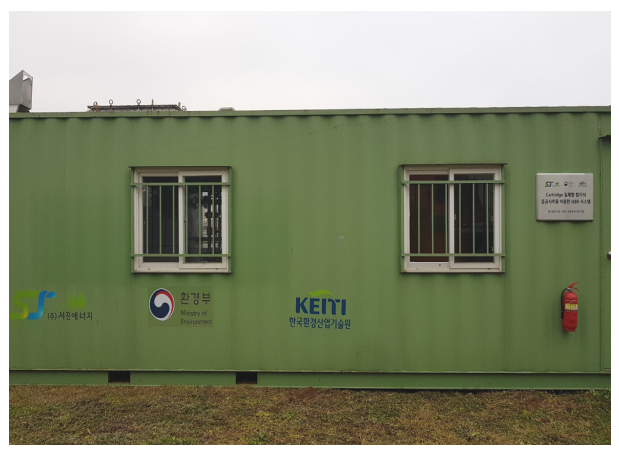

(a)

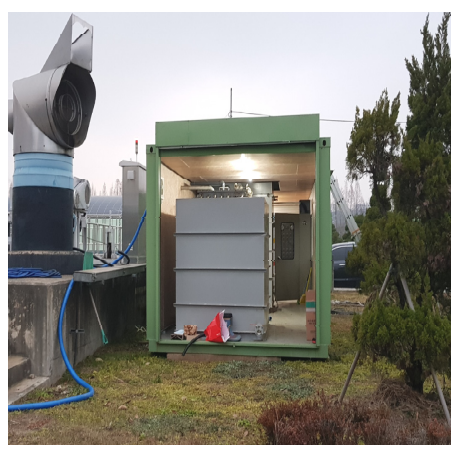

(b)

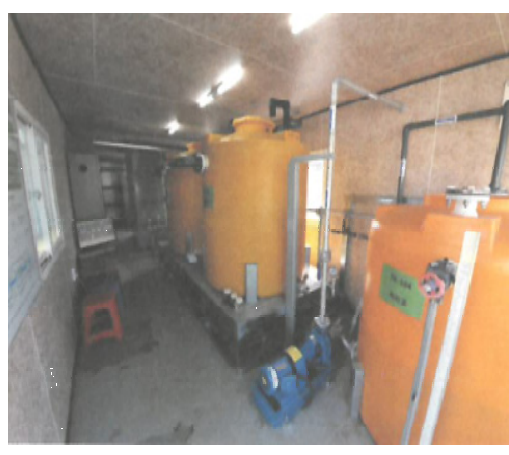

(c)

Fig. 6. Installation view of the SJMBR pilot plant: (a) front view, (b) side view, (c) interior view. 

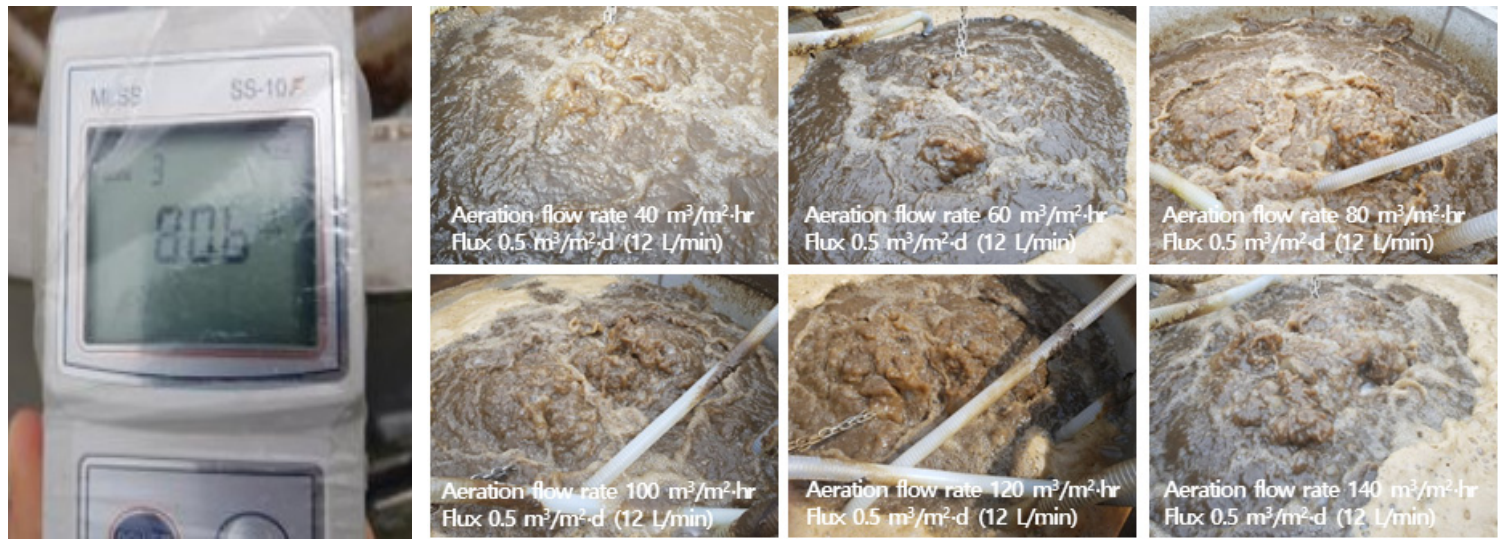

Fig. 7. MLSS concentration and scouring aeration $\left(40 \sim 140 \mathrm{~m}^{3} / \mathrm{m}^{2} \cdot \mathrm{hr}\right)$ in aerobic/membrane tank.

Table 3. Calculation factors for $\mathrm{SAD}_{m}$ and $\mathrm{SAD}_{p}$ of $\mathrm{SJMBR}$

\begin{tabular}{|c|c|}
\hline Item & Value \\
\hline Flow rate & $14.0 \mathrm{~m}^{3} / \mathrm{d}$ \\
\hline Flux & $0.5 \mathrm{~m}^{3} / \mathrm{m}^{2} \cdot \mathrm{hr}(21.0 \mathrm{LMH})$ \\
\hline Area & $28.0 \mathrm{~m}^{2}$ \\
\hline Aeration & $7.2 \mathrm{~m}^{3} / \mathrm{hr}$ \\
\hline$S A D_{m}=\frac{Q_{\text {Air }}}{A_{\text {Membrane }}}$ & $=\frac{7.2 \mathrm{Nm}^{3} / \mathrm{hr}}{28.0 \mathrm{~m}^{2}}=0.26 \mathrm{Nm}^{3} / \mathrm{hr}-\mathrm{m}^{2}$ \\
\hline$S A D_{p}=\frac{Q_{\text {Air }}}{A_{\text {Permeate }}}=$ & $\frac{7.2 \mathrm{Nm}^{3} / \mathrm{hr} \times 24 \mathrm{hr}}{14.0 \mathrm{~m}^{3} / \mathrm{d}}=12.34 \mathrm{Nm}^{3} / \mathrm{m}^{3}$ \\
\hline
\end{tabular}

을 통해 주요 제조사들과의 공기공급량을 비교하였다. ${ }^{19,20)}$

\section{3. 결과 및 고찰}

공기세정 일체형 중공사막 모듈을 이용한 막 오염 제어를 위한 실험결과는 다음과 같다.

\section{1. $\mathrm{SAD}_{m}$ 및 $\mathrm{SAD}_{p}$ 산출결과}

본 연구의 $\mathrm{SAD}_{m}, \mathrm{SAD}_{p}$ 산출내역과 결과는 다음과 같다 (Table 3).

산출결과 $\mathrm{SAD}_{m}$ 은 $0.26 \mathrm{~m}^{3} / \mathrm{m}^{2} \cdot \mathrm{hr}, \mathrm{SAD}_{p}$ 는 $12.34 \mathrm{~m}^{3} / \mathrm{m}^{2}$ 로 나타났다. 주요 제조사들의 경우 $\mathrm{SAD}_{m}$ 은 $0.3 \sim 0.8 \mathrm{~m}^{3} / \mathrm{m}^{2} \cdot \mathrm{hr}$, $\mathrm{SAD}_{p}$ 는 $10 \sim 90 \mathrm{~m}^{3} / \mathrm{m}^{2}$ 로 조사되었다. ${ }^{19,20)}$

산출 및 조사결과를 비교시 공기공급량이 감소되어 에너지 저감이 가능할 것으로 판단된다.

\section{2. 세정공기 공급량에 따른 막 오염 영향}

\subsection{1. 청수를 이용한 플럭스 및 압력 영향 평가}

공기세정 일체형 중공사막을 적용한 청수 실험은 세정공기 공급량을 $40 \sim 140 \mathrm{~m}^{3} / \mathrm{m}^{2} \cdot \mathrm{hr}$ 의 범위로 조절하였으며, 투과플 럭스는 $0.5 \sim 1.0 \mathrm{~m}^{3} / \mathrm{m}^{2} \cdot \mathrm{d}(21.0 \sim 42.0 \mathrm{LMH})$ 의 범위로 조절하여 투과압력에 미치는 영향을 평가한 결과는 다음과 같다(Fig. 8).

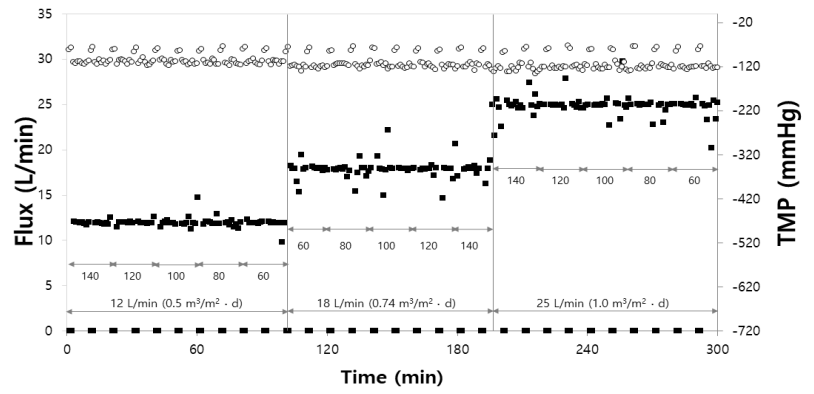

Fig. 8. Effects of scouring aeration flow rate on flux ( $\square$ ) and transmembrane pressure $(O)$ using tap water.

각각의 투과플럭스 조건에서 공기공급량 변화에 따른 투과 압력을 관찰한 결과, 투과압력의 증가 및 감소에 대한 영향은 없는 것으로 판단된다.

위 실험을 토대로 막 오염 현상 없이 운영되는 투과압력은 가동시 $-120.0 \mathrm{mmHg}$ 이하, 정지시 $-100.0 \mathrm{mmHg}$ 이하로 확인 할 수 있었다.

또한, 위 실험결과를 토대로 가동시와 정지시의 초기투과압 력 기준을 확인할 수 있었다.

\subsection{2. 하수를 이용한 플럭스 및 압력 영향 평가}

세정공기 공급량을 $140 \mathrm{~m}^{3} / \mathrm{m}^{2} \cdot \mathrm{hr}$ 로 조절하였고, 투과플럭 스는 $0.5 \mathrm{~m}^{3} / \mathrm{m}^{2} \cdot \mathrm{d}(21.0 \mathrm{LMH})$ 로 운전한 결과는 Fig. 9(a)와 같다. 세정공기량을 투영면적당 $140 \mathrm{~m}^{3} / \mathrm{m}^{2} \cdot \mathrm{hr}$ 공급한 결과, 투과압력 및 투과플럭스가 안정적으로 유지되는 것을 확인하 였다.

세정공기 공급량을 $120 \mathrm{~m}^{3} / \mathrm{m}^{2} \cdot \mathrm{hr}$ 로 조절하였고, 투과플럭 스는 $0.5 \mathrm{~m}^{3} / \mathrm{m}^{2} \cdot \mathrm{d}(21.0 \mathrm{LMH})$ 로 운전한 결과는 Fig. 9(b)와 같다. 세정공기량을 투영면적당 $120 \mathrm{~m}^{3} / \mathrm{m}^{2} \cdot \mathrm{hr}$ 공급한 결과, 투과압력 및 투과플럭스가 안정적으로 유지되는 것을 확인하 였다.

세정공기 공급량을 $100 \mathrm{~m}^{3} / \mathrm{m}^{2} \cdot \mathrm{hr}$ 로 조절하였고, 투과플럭 스는 $0.5 \mathrm{~m}^{3} / \mathrm{m}^{2} \cdot \mathrm{d}(21.0 \mathrm{LMH})$ 로 진행한 결과는 Fig. 9(c)와 


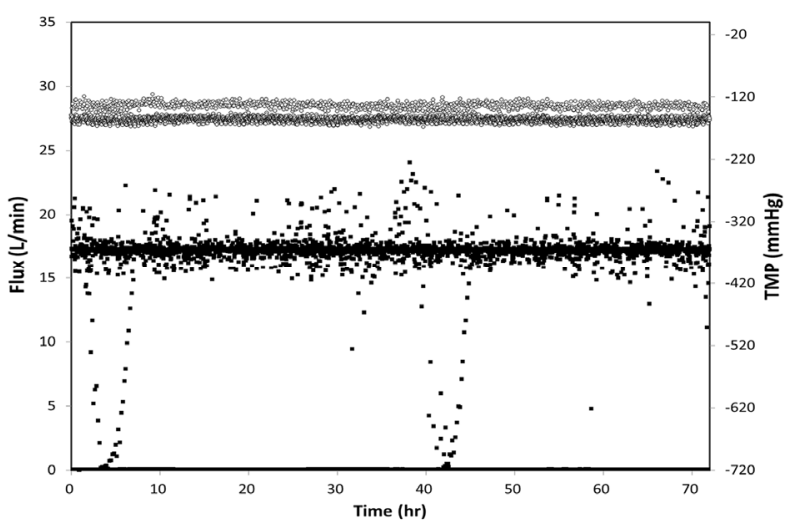

(a)

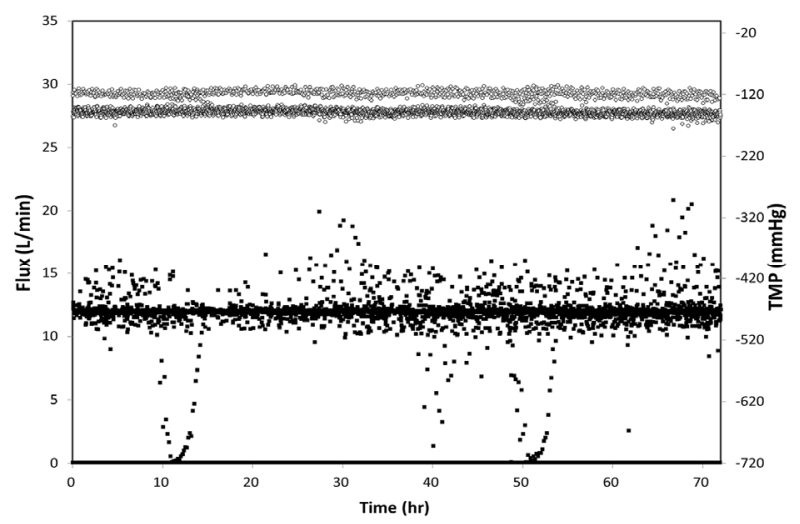

(c)

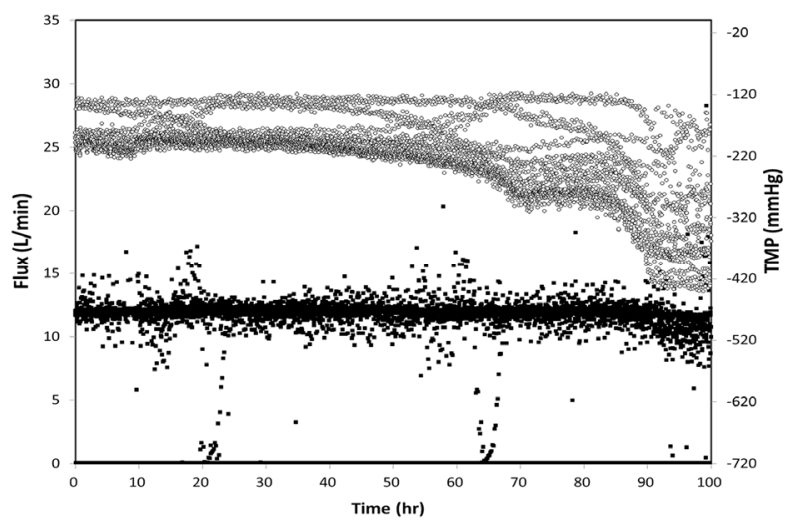

(e)

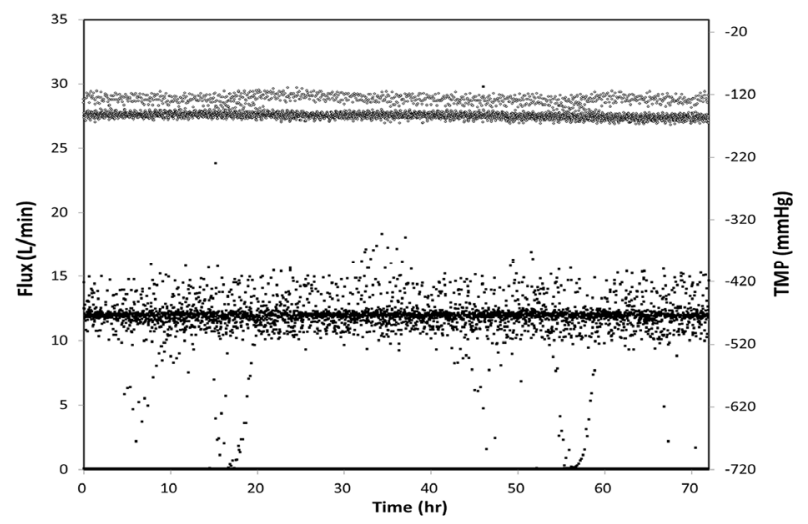

(b)

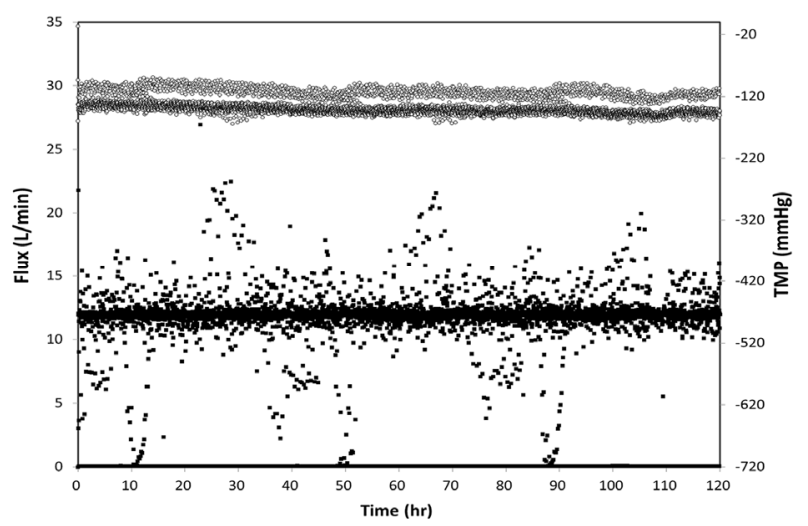

(d)

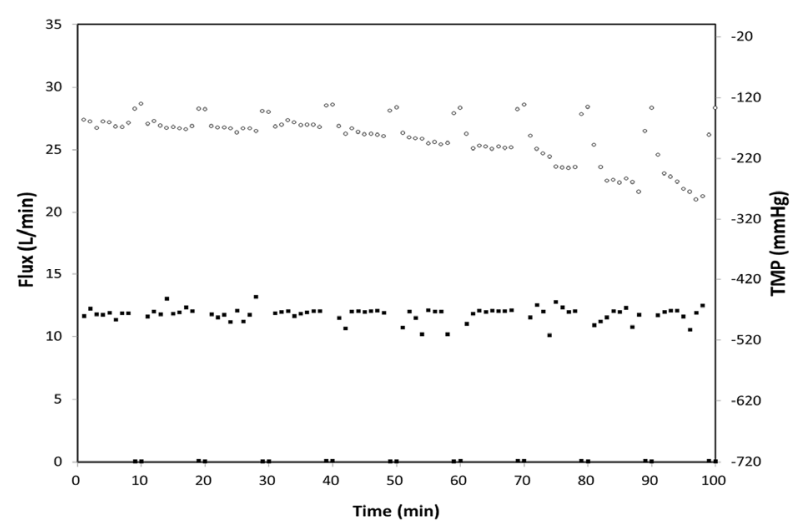

(f)

Fig. 9. Effect of scouring aeration rate on flux $(\boldsymbol{\square})$ and transmembrane pressure (TMP, $O$ ) in domestic wastewater with MLSS of $8,000 \mathrm{mg} / \mathrm{L}$ (a) 140 , (b) 120 , (c) 100 , (d) 80 , (e) 60 , (f) $40 \mathrm{~m}^{3} / \mathrm{m}^{2} \cdot \mathrm{hr}$, respectively.

같다. 세정공기량을 투영면적당 $100 \mathrm{~m}^{3} / \mathrm{m}^{2} \cdot \mathrm{hr}$ 공급한 결과, 투과압력 및 투과플럭스가 안정적으로 유지되는 것을 확인하 였다.

세정공기 공급량을 $80 \mathrm{~m}^{3} / \mathrm{m}^{2} \cdot \mathrm{hr}$ 로 조절하였고, 투과플럭스 는 $0.5 \mathrm{~m}^{3} / \mathrm{m}^{2} \cdot \mathrm{d}(21.0 \mathrm{LMH})$ 로 운전한 결과는 Fig. 9(d)와 같 다. 세정공기량을 투영면적당 $80 \mathrm{~m}^{3} / \mathrm{m}^{2} \cdot \mathrm{hr}$ 공급한 결과, 투과 압력 및 투과플럭스가 안정적으로 유지되는 것을 확인하였 다. 실험결과는 일반적인 기존 제조사별 세정공기량보다 공
급량이 감소되었음에도 불구하고 안정적인 투과플럭스를 확 보할 수 있는 것으로 판단할 수 있다. 또한, 세정공기량 공급 의 감소를 통해 에너지 저감 효과를 확인하기 위해 전력사용 량 및 유지관리비를 산출하였다(Table4). 전력사용량의 산정 기준은 정량적 산출을 위해 $14.0 \mathrm{~m}^{3} / \mathrm{d}$ 처리용량의 pilot test의 산출결과를 토대로 $140 \mathrm{~m}^{3} / \mathrm{d}$ 의 full-scale 처리용량으로 가정 하여 송풍기 제조사의 roots type 송풍기(SL065, Korea Fluid Machinery, Korea) 성능표를 기준으로 사용전력량을 산출하 
Table 4. Comparison of amount of electricity used and annual maintenance costs (Assume that plant capacity is $140 \mathrm{~m}^{3} / \mathrm{d}$ ). ${ }^{21,22)}$

\begin{tabular}{ccc} 
Item & Existing MBR & SJMBR \\
Aeration flow & $1.5 \sim 2.1 \mathrm{~m}^{3} / \mathrm{min}$ & $1.2 \mathrm{~m}^{3} / \mathrm{min}$ \\
\hline Air capacity of roots blower & $2.25 \sim 2.86 \mathrm{~m}^{3} / \mathrm{min}$ & $1.63 \mathrm{~m}^{3} / \mathrm{min}$ \\
\hline Driving power of roots blower & $3.19 \sim 3.87 \mathrm{~kW}$ & $2.44 \mathrm{~kW}$ \\
\hline Power consumption & $76.56 \sim 92.88 \mathrm{~kW}$ & $58.56 \mathrm{~kW}$ \\
\hline Electricity cost & $2,490,000 \sim 3,010,000 \mathrm{KRW} /$ year & $1,900,000 \mathrm{KRW} /$ year \\
\hline Energy saving efficiency & - & Reduced to more than $23.5 \%$ \\
\hline
\end{tabular}

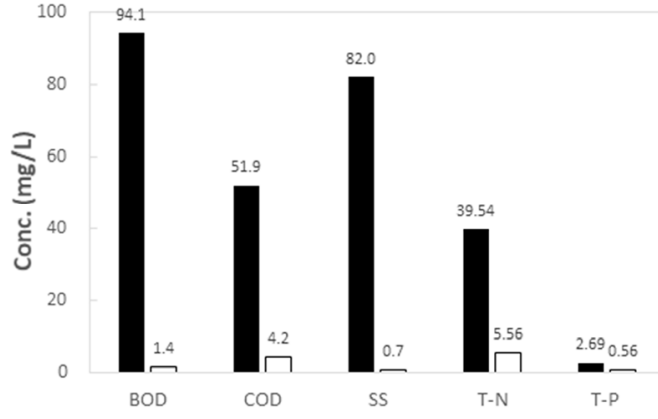

(a)

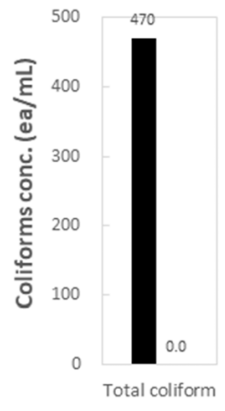

(b)

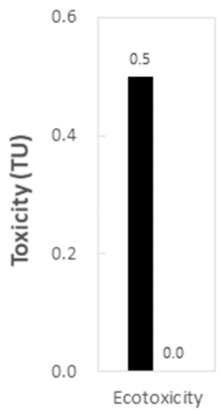

(c)

Fig. 10. Comparison of influent( $\square$ ) and effluent( $\square$ ) (a) BOD, COD, SS, T-N, T-P, (b) coliform group, (c) ecotoxicity, respectively.

였다. ${ }^{21)}$ 유지관리비(세정공기 공급 공기량에 한함)는 산출한 사용전력량을 토대로 한국전력공사에서 제공하는 전기요금 표[산업용(을), 고압A, 선택 II]를 기준으로 산출하였으며, 이 중 전력사용요금 외 기본요금 및 전력기금 등의 추가요금은 산출에서 제외하였다. ${ }^{22)}$

Table 4의 산출내역을 확인한 결과, 세정공기량 공급의 감 소를 통해 최소 $20 \%$ 의 에너지 저감 효과를 기대할 수 있을 것으로 판단된다.

실험 조건으로 세정공기 공급량을 $60 \mathrm{~m}^{3} / \mathrm{m}^{2} \cdot \mathrm{hr}$ 로 조절하고, 투과플럭스를 $0.5 \mathrm{~m}^{3} / \mathrm{m}^{2} \cdot \mathrm{d}(21.0 \mathrm{LMH})$ 로 진행한 결과는 Fig. 9(e)와 같다. 세정공기량을 투영면적당 $60 \mathrm{~m}^{3} / \mathrm{m}^{2} \cdot \mathrm{hr}$ 공급한 결과, 시간이 경과됨에 따라 투과압력이 점진적으로 상승되었 으며, 임계투과압력까지 상승 후에는 처리유량이 감소되는 것 으로 확인되었다. 이는 막 오염이 제어에 필요한 공급량보다 부족하여 막 오염이 진행된 것으로 판단된다.

실험 조건으로 세정공기 공급량을 $40 \mathrm{~m}^{3} / \mathrm{m}^{2} \cdot \mathrm{hr}$ 로 조절하고, 투과플럭스를 $0.5 \mathrm{~m}^{3} / \mathrm{m}^{2} \cdot \mathrm{d}(21.0 \mathrm{LMH})$ 로 진행한 결과는 Fig. 9(f)와 같다. 세정공기량을 투영면적당 $40 \mathrm{~m}^{3} / \mathrm{m}^{2} \cdot \mathrm{hr}$ 공급한 결과, 실험 시작 후 100 분이 채 되기 전 투과압력이 급격한 상승 경향을 보였으며, 이는 투영면적당 $60 \mathrm{~m}^{3} / \mathrm{m}^{2} \cdot \mathrm{hr}$ 공급한 결과와 마찬가지로, 막 오염 제어에 필요한 공급량보다 부족 하여 막 오염이 진행된 것으로 판단된다.

\subsection{SJMBR 수질분석 결과}

SJMBR pilot plant 운전 중 유입수와 처리수의 수질분석한 결과, 처리수의 $\mathrm{BOD}, \mathrm{COD}, \mathrm{TN}, \mathrm{TP}, \mathrm{SS}$ 항목은 방류수 수질
기준을 만족하고 있으며, 생태독성 및 총대장균도 완벽하게 제거되는 것으로 나타났다(Fig. 10).

처리수를 분석결과, $\mathrm{BOD} 1.4 \mathrm{mg} / \mathrm{L}, \mathrm{COD} 4.7 \mathrm{mg} / \mathrm{L}, \mathrm{SS} 0.7$ $\mathrm{mg} / \mathrm{L}, \mathrm{T}-\mathrm{N} 5.56 \mathrm{mg} / \mathrm{L}, \mathrm{T}-\mathrm{P} 0.56 \mathrm{mg} / \mathrm{L}$, 생태독성 $0.0 \mathrm{TU}$, 총대 장균군 0 개 $/ \mathrm{mL}$ 으로 분석되었으며, 제거율은 $\mathrm{BOD} 98.5 \%$, $\mathrm{COD} 91.9 \%$, SS $99.1 \%$, T-N $85.9 \%$, T-P $79.2 \%$, 생태독성 $100.0 \%$, 총대장균군 $100.0 \%$ 으로 나타났다.

\section{4. 결 론}

본 연구에서는 에너지 및 막 오염 저감을 위해 공기세정 일 체형 중공사막 모듈을 적용하여 세정공기량에 따른 분리막 모듈의 성능을 평가하였으며, 다음의 결론을 얻을 수 있었다.

1) 프레임 투영면적당 세정공기 공급량을 $40 \sim 140 \mathrm{~m}^{3} / \mathrm{m}^{2}$. $\mathrm{hr}$ 의 범위에서 투과플럭스 및 압력에 미치는 영향을 평가한 결과, 분리막 성능에 영향을 미치지 않는 세정공기 최적공급 량은 $80 \mathrm{~m}^{3} / \mathrm{m}^{2}$ projected $\mathrm{area} \cdot \mathrm{hr}$ 으로 확인되었다.

2) Pilot plant의 처리수를 분석한 결과, BOD $1.4 \mathrm{mg} / \mathrm{L}$, COD $4.7 \mathrm{mg} / \mathrm{L}$, SS $0.7 \mathrm{mg} / \mathrm{L}$, T-N $5.56 \mathrm{mg} / \mathrm{L}$, T-P $0.56 \mathrm{mg} / \mathrm{L}$, 생태독성 $0.0 \mathrm{TU}$, 총대장균군 0 개/L으로 나타났다. 제거율은 BOD 98.5\%, COD 91.9\%, SS 99.1\%, T-N 85.9\%, T-P 79.2\%, 생태독성 $100.0 \%$, 총대장균군 $100.0 \%$ 으로 나타나, 안정적인 처리수질을 확보할 수 있는 것으로 확인되었다.

공기세정 일체형 중공사막 모듈은 기존의 분리막과 동등한 수준의 투과성능과 수질만족에 부합하는 기술로써, 세정공기 공급량을 최적화하여 기존 대비 $20 \%$ 이상의 세정공기량 저감 
효과를 기대할 수 있을 것으로 판단된다.

\section{Acknowledgement}

본 연구는 정부(환경부)의 재원으로 한국환경산업기술원의 2020년 중소환경기업 사업화 - 상용화 지원사업의 연구비 지 원으로 수행되었습니다(과제번호: L120-00006-0002-0). 이에 감사드립니다.

\section{References}

1. E. T. Yang, H. M. Kim, H. B. Jee, S. H. Song, C. K. Choi, The status and future development direction of the water industry in Gyeongsangnam-do province, J. Korean Soc. Environ. Eng., 43(4), 307-318(2021).

2. J. M. Park, W. T. Lee, Effect of oxidant addition on water quality and microfiltration performance during water reclamation, J. Korean Soc. Environ. Eng., 42(4), 210-217 (2020).

3. G. Ferrero, I. Rodriguez-Roda, J. Comas, Automatic control systems for submerged membrane bioreactors: a state of the art review, Water Res., 46(11), 3421-3433(2012).

4. B. Lesjean, V. Ferre, E. Vonghia, H. Moeslang, Market and design consideration of the 37 larger MBR plants in europe, Desalin. Water Treat., 6(1-3), 227-233(2009).

5. A. Santos, W. Ma, S. J. Judd, Membrane bioreactors: two decades of research and implementation, Desalination, 273(1), 148-154(2011).

6. K. Sutherland, The rise of membrane bioreactors, Filtr. Separat., 47(5), 14-16(2010).

7. H. D. Park, I. S. Chang, K. J. Lee, Principles of membrane bioreactors for wastewater treatment, CRC press, Boca Raton, United States, pp. 2-3(2015).

8. S. Judd, The status of membrane bioreactor technology, Trends Biotechnol., 26(2), 109-116(2008).

9. N. Savla, S. Pandit, N. Khanna, A. S. Mathuriya, S. H. P. Jung, Microbially powered electrochemical systems coupled with membrane-based technology for sustainable desalination and efficient wastewater treatment, J. Korean Soc. Environ. Eng., 42(7), 360-380(2020).

10. A. Drews, Membrane fouling in membrane bioreactors: characterization, contradictions, cause and cures, J. Membrane Sci, 363(1-2), 1-28(2010).

11. S. H. Yoon, Membrane bioreactor processes principles and applications, CRC press, Boca Raton, United States, pp. 270-272(2016).

12. J. S. Kim, Y. L. Kuk, J. Y. Park, Y. J. Jang, C. H. Park, A study on membrane fouling control by immobilized microbial media for nitrification in membrane bioreactor, J. Korean Soc. Environ. Eng., 41(5), 272-277(2019).

13. S. H. Yoon, Membrane bioreactor processes principles and applications, CRC press, Boca Raton, United States, pp. 119-124(2016).
14. Ministry of Environment, Master Plan for Energy Selfreliance, Ministry of Environment, Sejong, Korea, pp. 3-4 (2010).

15. T. Ueda, K. Hata, Y. Kikuoka, Treatment of domestic sewage from rural settlements by a membrane bioreactor, Water Sci. Technol., 34(9), 189-196(1996).

16. I. H. Cho, J. T., Kim, Trends in the technology and market of membrane bioreactor (MBR) for wastewater treatment and reuse and development directions, Membr. J., 23(1), 24-44(2013).

17. H. Monclús, M. Dalmau, S. Gabarrón, G. Ferrero, I. Rodríguez-Roda, J. Comas, Full scale validation of an air scour control system for energy savings in membrane bioreactors, Water Res., 79, 1-9(2015).

18. H. D. Park, I. S. Chang, K. J. Lee, Principles of membrane bioreactors for wastewater treatment, CRC press, Boca Raton, United States, pp. 100-105(2015).

19. S. H. Yoon, Membrane bioreactor processes principles and applications, CRC press, Boca Raton, United States, pp. 104-107, 270(2016).

20. H. D. Park, I. S. Chang, K. J. Lee, Principles of membrane bioreactors for wastewater treatment, CRC press, Boca Raton, United States, pp. 166-168(2015)

21. Korea Fluid Machinery Home Page, http://www.kfmblower. co.kr/sub02_03_05.html, June(2021).

22. Korea Electric Power Corporation Home Page, https://cyber.kep co.co.kr/ckepco/front/jsp/CY/E/E/CYEEHP00103.jsp\#, June(2021).

\section{Declaration of Competing Interest}

The authors declare that they have no known competing financial interests or personal relationships that could have appeared to influence the work reported in this paper.

\section{Authors and Contribution Statement}

\section{Hyun-Hoon Jung}

Seojin Energy Co., Ltd., Department of Environmental Engineering, Catholic Kwandong University, Assistant Manager, Ph. D. Candidate, ORCID (1) 0000-0003-0448-6848: Conceptualization, Data curation, Data analysis, Methodology, Visualization, Writing - original draft, Writing - review and editing.

\section{Ji-yun Seon}

Seojin Energy Co., Ltd., Senior Researcher, ORCiD (두 0000-00024582-0657: Funding acquisition, Project administration, Data analysis, Writing - review and editing.

\section{Tea-Hyoung Lim}

Seojin Energy Co., Ltd., President, ORCiD 두 0000-0001-5619-0104: Writing - review and editing. 
Hyun-Hoon Jung et al.

\section{Seung-Mok Lee}

Department of Environmental Engineering, Catholic Kwandong University, Professor, ORCID(D) 0000-0003-0240-4888: Writing review and editing.

\section{Seung-Kyun Park}

Seojin Energy Co., Ltd., Vice President, ORCID ํㅣ 0000-0002-8951 -0984: Conceptualization, Data curation, Data analysis, Methodology, Visualization, Writing - original draft. 